\title{
DNA-PK is a DNA sensor for IRF-3-dependent innate immunity
}

\author{
Brian J Ferguson ${ }^{1,2 \ddagger}$, Daniel S Mansur ${ }^{1 \ddagger \ddagger}$, Nicholas E Peters ${ }^{1 \neq}$, Hongwei Ren ${ }^{1,2}$, \\ Geoffrey L Smith ${ }^{1,2 *}$
}

${ }^{1}$ Department of Virology, Imperial College London, London, United Kingdom; ${ }^{2}$ Department of Pathology, University of Cambridge, Cambridge, United Kingdom

*For correspondence: gls37@cam.ac.uk

†Present address: Laboratory of Immunobiology, Departmento de Microbiologia, Imunologiae Parasitologia, Universidade Federal de Santa Catarina, Florianopolis, Brazil

₹These authors contributed equally to this work

Competing interests: The authors have declared that no competing interests exist

Funding: See page 15

Received: 06 July 2012

Accepted: 24 October 2012

Published: 18 December 2012

Reviewing editor: Ruslan Medzhitov, Yale University, United States

(c) Copyright Ferguson et al. This article is distributed under the terms of the Creative Commons Attribution License, which permits unrestricted use and redistribution provided that the original author and source are credited.

\begin{abstract}
Innate immunity is the first immunological defence against pathogens. During virus infection detection of nucleic acids is crucial for the inflammatory response. Here we identify DNA-dependent protein kinase (DNA-PK) as a DNA sensor that activates innate immunity. We show that DNA-PK acts as a pattern recognition receptor, binding cytoplasmic DNA and triggering the transcription of type I interferon (IFN), cytokine and chemokine genes in a manner dependent on IFN regulatory factor 3 (IRF-3), TANK-binding kinase 1 (TBK1) and stimulator of interferon genes (STING). Both cells and mice lacking DNA-PKcs show attenuated cytokine responses to both DNA and DNA viruses but not to RNA or RNA virus infection. DNA-PK has well-established functions in the DNA repair and $V(D) J$ recombination, hence loss of DNA-PK leads to severe combined immunodeficiency (SCID). However, we now define a novel anti-microbial function for DNA-PK, a finding with implications for host defence, vaccine development and autoimmunity.

DOI: 10.7554/eLife.00047.001
\end{abstract}

\section{Introduction}

The innate immune response is mediated by the production of cytokines, including type I interferons (IFNs), and chemokines following the detection of pathogen-specific molecules by host cells (Akira et alo, 2006; Medzhitov, 2007). Detection of nucleic acids is crucial in triggering the innate immune to pathogens, particularly in response to viruses (Pichlmair and Reis e Sousa, 2007). Various double and single stranded RNA substrates are recognised directly by the DExD/H box RNA helicases retinoic acid-inducible gene I (RIG-I) and melanoma differentiation-associated gene-5 (MDA-5) in the cytoplasm and by the endosomal toll-like receptors (TLRs) (Pichlmair and Reis e Sousa, 2007). The engagement of such RNA receptors leads to the rapid transcription of genes encoding anti-viral proteins via the activation of transcription factors belonging to the interferon regulatory factor (IRF) and nuclear factor-kappa B (NF-KB) families. It has been recognised for some time that intracellular DNA can activate a similar IRF-3-dependent innate immune response (Stetson and Medzhitov, 2006) and it is known that this signalling pathway depends on both the IRF-3-activating kinase, TANK-binding kinase 1 (TBK1) (Ishii et al., 2006, 2008) and the adaptor protein stimulator of IFN genes (STING-also known as MITA, ERIS and TMEM173) (Ishikawa et al., 2009). Only more recently, however, have some candidate receptors for these pathways been identified. DNA-dependent activator of IFN-regulatory factors (DAI) (Takaoka et al., 2007), RNA polymerase III (RNA-Pol III) (Ablasser et al., 2009; Chiu et al., 2009), IFN inducible gene 16 (Unterholzner et al., 2010) and DDX41 (Zhang et al., 2011b) have been described as cytoplasmic DNA sensors that activate IRF-3. Nonetheless, the in vivo relevance of these sensors remains unknown and the normal immune response to DNA stimulation of $\mathrm{Dai}^{-1-}$ and $I p s 1^{-1-}$ cells (Ishii et al., 2008; Wang et al., 2008) and sensing of plasmodium DNA independent of these receptors (Sharma et al., 2011) indicates other IRF-3-activating cytoplasmic DNA sensors exist. In addition, although TBK1 and STING are essential for activation of IRF-3 following DNA stimulation, the molecular details of this signalling pathway are poorly understood (Paludan et al., 2011; Barber, 2011). 
eLife digest For multicellular organisms, the innate immune system is the first immunological defence against infection, rapidly recognizing and responding to the presence of any pathogen. Many different cell types contribute to the innate immunity, including fibroblasts, epithelial cells, dendritic cells and macrophages. Once alerted to injury or infection, these cells release proteins called cytokines, interferons and chemokines into the blood or directly into tissue. These proteins act as messengers and interact with receptors on the surfaces of other cells in the immune system, stimulating them to join the battle against the infection.

Detecting nucleic acids such as DNA is an important part of recognizing pathogens and infectious agents, particularly viruses, and activating the innate immune system. However, while the presence of DNA in the cytoplasm is known to initiate an innate immune response, we do not fully understand how this foreign DNA is sensed, or how the innate immune system is activated once foreign DNA has been detected.

Here Ferguson et al. report that a well-known complex of three proteins, collectively called DNA-dependent protein kinase, is able to activate an innate immune response when it detects foreign DNA. This enzyme, called DNA-PK for short, is best known for its ability to repair broken DNA inside the nucleus. Now Ferguson et al. have found that it is also present at high levels within fibroblasts, cells that are often primary targets of viral infection, and they go on to explain how the detection of DNA by DNA-PK triggers a sequence of events that leads to the innate immune response being activated. These events include the transcription of type I interferon, chemokines and cytokines in a manner that depends on the presence IRF-3, a transcription factor that has a central role in the response of the immune system to viral infection.

By identifying a role for DNA-PK in the cytoplasm as a DNA sensor, the work of Ferguson et al. increases our understanding of innate immunity. It may also, in the future, lead to an improved understanding of autoimmunity, and might also assist in the development of more immunogenic vaccines based on DNA or microbes that contain DNA.

DOI: 10.7554/eLife.00047.002

The presence of unidentified DNA sensors in fibroblasts is especially pertinent to virus infection since these cells are often a primary target of virus infection in vivo. These cells should have sentinel innate immune receptors in place to detect the presence of foreign nucleic acid and respond by producing IFN, cytokines and chemokines to initiate the anti-viral state in the surrounding tissue as well as to attract immune cells to the site of infection. In this study we identify DNA-dependent protein kinase (DNA-PK) as a novel DNA sensor in fibroblasts where it is present at high levels enabling it to respond to incoming infection without the need for prior stimulation. DNA-PK is a heterotrimeric protein complex consisting of three proteins, Ku70, Ku80 (also known as Ku86) and the catalytic subunit DNA-PKcs (encoded by the xrcc6, xrcc5 and prkcd genes respectively). Ku70 and Ku80 themselves form a heterodimer and the absence of one subunit de-stabilises the expression of the other (Nussenzweig et al., 1996; Gu et al., 1997). Both the Ku heterodimer (Walker et al., 2001) and DNA-PKcs (Hammarsten and Chu, 1998) can bind directly to DNA but, in the absence of Ku the affinity of DNA-PKcs for DNA is greatly reduced (Yaneva et al., 1997). DNA-PK has a well described role in the nucleus where it is necessary for non-homologous end joining (NHEJ) and so has a key role in repairing double-strand DNA breaks (Lieber et al., 2003). DNA-PK has also been detected in the cytoplasm by immunofluorescence and cell fractionation (Huston et al., 2008; Balazs et al., 2012), although prior to this study no function has been assigned to DNA-PK in this localisation. Here we found that, in the cytoplasm, DNA-PK signals via IRF-3 to activate an anti-microbial innate immune response to DNA mediated by the production of IFN, cytokines and chemokines. We show that DNA-PK co-localises with sites of viral DNA replication during VACV infection and the innate immune response to DNA and to infection with vaccinia virus (VACV) and herpes simplex virus (HSV-1) was impaired in both cells and mice which lack components of DNA-PK.

\section{Results}

\section{DNA-PK binds DNA in the cytoplasm}

To identify novel cytoplasmic DNA sensors, we transfected biotinylated dsDNA composed of a concatenated 45-bp oligonucleotide (called immunostimulatory DNA, ISD, (Stetson and Medzhitov, 2006)) 


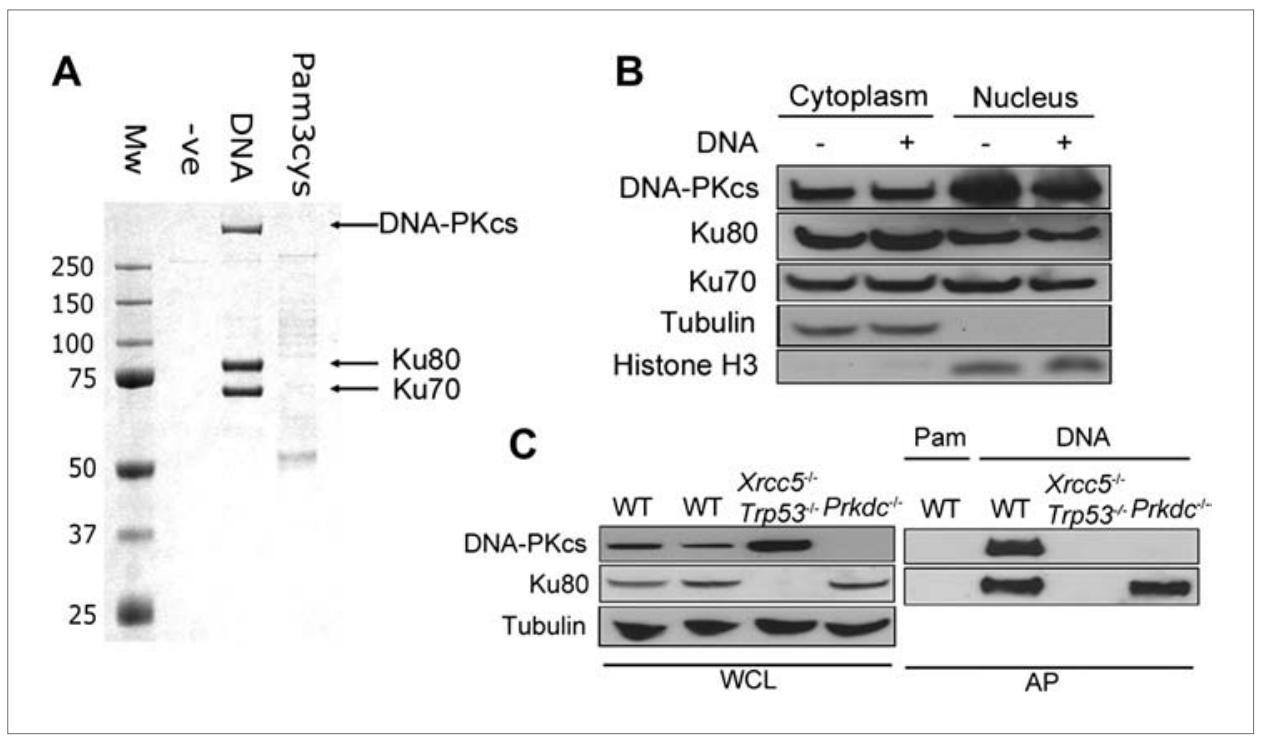

Figure 1. DNA-PK binds DNA in the cytoplasm. (A) Biotinylated DNA or biotinylated pam-3-cys were transfected into HEK 293T cells and 30 min later DNA was affinity purified from the cytoplasmic fraction before analysis of DNA/protein complexes by SDS-PAGE. The three major protein bands visible by coomassie blue staining were excised from the gel and identified as Ku70, Ku80 and DNA-PKcs by mass spectrometry. (B) Cells were untreated or transfected with DNA and $2 \mathrm{hr}$ later proteins were extracted from the nucleus and cytoplasm. $50 \mathrm{\mu g}$ of protein from each fraction (representing $10 \%$ of total cytoplasmic protein by volume and $5 \%$ of the total nuclear protein) was analysed by immunoblotting for DNA-PKcs, Ku70 and Ku80. $\beta$-tubulin and histone-H3 were used as controls to indicate successful fractionation. (C) Ku80 is required for efficient binding to DNA. MEFs of indicated genotypes were transfected with DNA biotinylated at the 3' end or biotinylated pam-3-cys (Pam) and lysed 1 hr later. Following affinity purification (AP) of biotinylated ligands with streptavidin agarose, proteins were analysed by SDS-PAGE and immunoblotting for DNA-PKcs and Ku80. WCL; whole cell lysate.

DOI: 10.7554/eLife.00047.003

into human embryonic kidney (HEK) 293T cells and isolated DNA/protein complexes from the cytoplasm by affinity purification (Figure 1A). The three abundant proteins that bound specifically to DNA, and not to biotinylated lipoprotein pam-3-cys, were unequivocally identified as Ku70, Ku80 and DNA-PKcs (Figure 1A). We confirmed by subcellular fractionation that DNA-PK is present in the cytoplasm of resting cells (Figure 1B), as reported previously (Huston et al., 2008; Balazs et al., 2012) and that this cytoplasmic localisation was not due to nuclear contamination (Figure 1B). The DNA pulldown was reproduced from murine fibroblasts (Figure 1C), showing the cross-species conservation of this interaction. Additionally, in murine embryonic fibroblasts (MEFs) lacking Ku80 ( $\mathrm{rcc5}^{-/-}$), the remaining DNA-PK components did not interact with cytoplasmic DNA under the conditions tested, whereas in Prkdc ${ }^{-1-}$ MEFs, Ku80 was still recruited (Figure 1C). Therefore, the association between DNA-PKcs and cytoplasmic DNA is enhanced by Ku.

\section{DNA-PK activates the innate immune response to DNA in fibroblasts}

In fibroblasts, the transcription of genes encoding chemokines and cytokines was induced in response to DNA in a length and dose-dependent manner, was sensitive to DNase treatment and required DNA to be transfected into the cell (Figure 2A and data not shown). These observations are consistent with other studies (Karayel et al., 2009; Unterholzner et al., 2010). Next we tested DNA from various sources, including vaccinia virus (VACV) and Escherichia coli, for its ability to bind DNA-PK in the cytoplasm and to stimulate $\mathrm{Cxc} / 10$ transcription. $\mathrm{Cxc} / 10$ is strongly induced by intracellular nucleic acids (Ishii et al., 2006) via the IRF-3- and NF-KB-binding sites in its promoter (Spurrell et al., 2005). Each of these different DNA species associated with DNA-PK in MEFs, and this association correlated with Cxcl10 induction (Figure 2B,C-black bars), implying DNA sequence-independence of this response. A similar correlation between DNA binding and 116 induction was also observed (data not shown).

Strikingly, in MEFs lacking DNA-PKcs $\left(\mathrm{Prkdc}^{-/-}\right)$there was a significant impairment in Cxcl10 transcription in response to double stranded concatenated ISD DNA (Stetson and Medzhitov, 2006) 


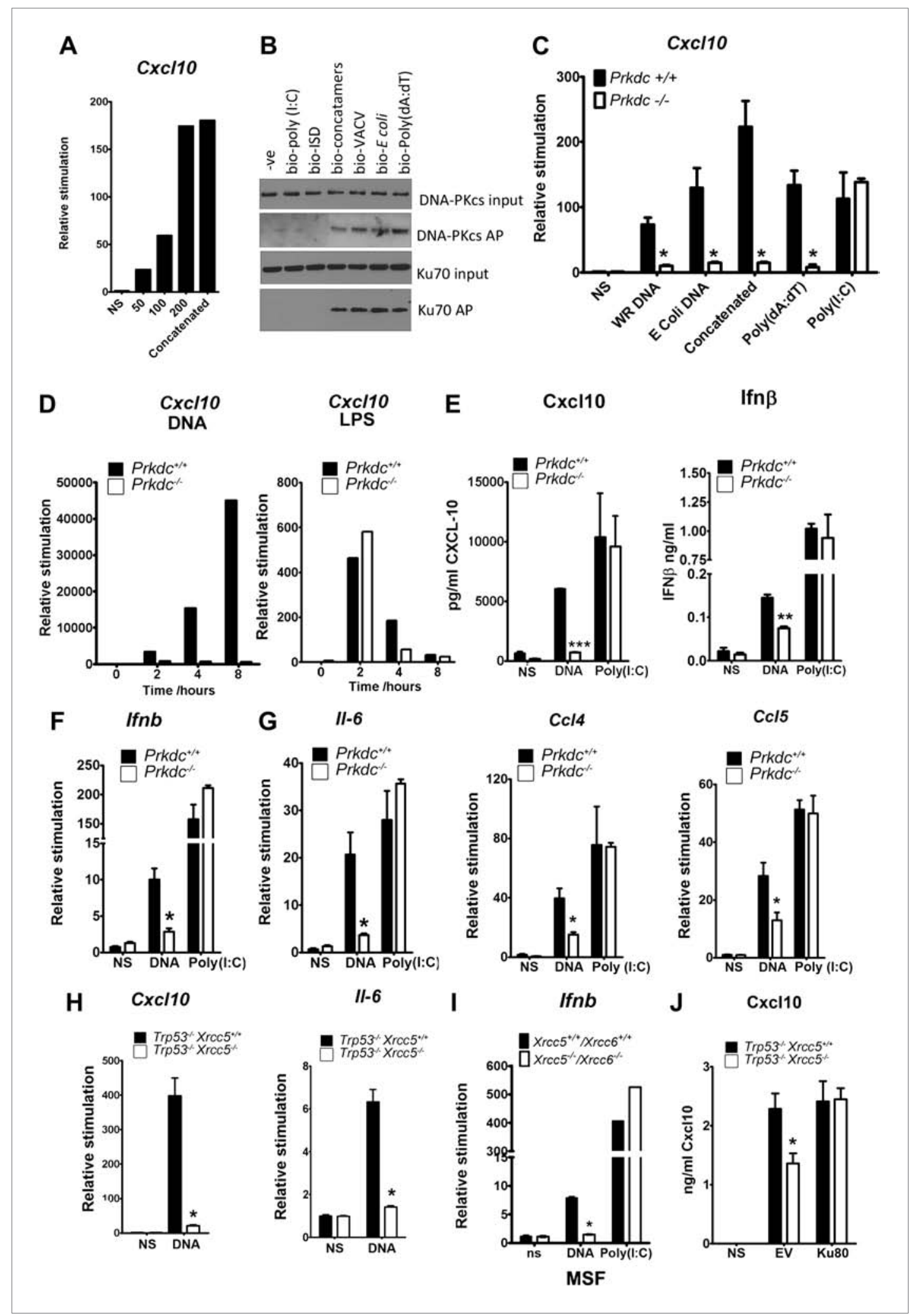

Figure 2. The innate immune response to DNA requires DNA-PK in fibroblasts. (A) ISD DNA of different lengths was transfected into MEFs and the transcription of Cxcl10 was assayed by qPCR 6 hr later. (B) Double stranded oligonucleotides (bio-ISD), concatenated ISD DNA (bio-concatamers), genomic vaccinia virus DNA (bio-VACV), genomic E. coli DNA (bio-E. coli), poly (dA:dT) or the RNA analogue poly (I:C) were biotinylated and transfected into HEK293 cells. Following affinity purification of proteins from cytoplasmic extracts using streptavidin Figure 2. Continued on next page 
Figure 2. Continued

agarose, the bound proteins were analysed by SDS-PAGE and immunoblotting. AP; affinity purification. (C) Primary MEFs of the indicated genotype were transfected with $10 \mu \mathrm{g} / \mathrm{ml}$ of the same (non-biotinylated) nucleic acids as in (A) followed by qRT-PCR analysis measuring induction of Cxcl10 mRNA 6 hr later. (D) Wild type and Prkdc ${ }^{-1-}$ transformed MEFs were transfected with DNA $(10 \mu \mathrm{g} / \mathrm{ml}$, left panel) or stimulated with LPS (100 $\mathrm{ng} / \mathrm{ml}$, right panel) and the level of transcription of $\mathrm{cxcl} 10$ was measured at the indicated times post stimulation. (E) Levels of $\mathrm{Cxc} / 10$ and Ifn $\beta$ were measured by ELISA from the supernatants of primary wild type and Prkdc ${ }^{-1-}$ MEFs at passage 1, $24 \mathrm{hr}$ after transfection with DNA or poly $(\mathbf{I}: \mathbf{C}) .(\mathbf{F}),(\mathbf{G})$ Primary wild type and Prkdc ${ }^{-1-}$ MEFs at passage 1 were transfected with DNA or poly (I:C) and the level of induction of (F) Ifnb and II-6 and (G) ccl4 and ccl5 mRNA was measured by qRT-PCR 6 hr later. (H) MEFs expressing Ku80 or lacking Ku80 were transfected with DNA and the transcription of Cxcl10 or 116 was measured by qPCR 6 hr later. (I) Primary murine skin fibroblasts (MSF) from wild type adult mice or those lacking both Ku genes were transfected with DNA or poly (I:C) and the level of Ifnb induction

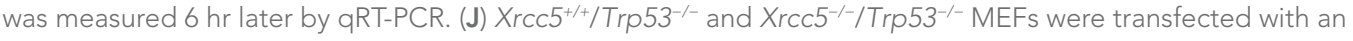
expression plasmid encoding Ku80 or an empty vector (EV) control and Cxcl10 production was measured $24 \mathrm{hr}$ later by ELISA. ${ }^{* * *} p<0.001,{ }^{* *} p<0.01,{ }^{*} p<0.05, n \geq 3$, error bars $\pm S E M, n s ;$ non-stimulated.

DOI: $10.7554 /$ eLife.00047.004

(from now on referred to as DNA), viral and bacterial DNA and poly(dA:dT) (Figure 2C, white bars). In contrast, the response to the dsRNA analogue, poly(l:C), was similar in the presence or absence of DNA-PKcs indicating the signalling defect is specific to DNA (Figure 2C). Time-course experiments indicated that the defect in DNA stimulation of Prkdc ${ }^{-1-}$ cells was consistent at all times tested (Figure 2D) and that these cells are not simply responding to DNA with different kinetics. The data presented in Figure 2C,D were carried out with MEFs derived from separate strains of Prkdc ${ }^{-1-}$ mice, indicating that this phenotype was not confined to a single MEF line. As a control we also tested the response to LPS (Figure 2D, right panel) and found the Prkdc ${ }^{-1-}$ cells responded like the wild type cells, with typically rapid kinetics, to this stimulus. In addition, the secretion of Cxcl10 and Ifn $\beta$ as well as the transcription of ifnb, il6, and the chemokines Ccl4 and Ccl5, was also consistently impaired in multiple preparations of passage $1 \mathrm{Prkdc}^{-/-} \mathrm{MEFs}$ in response to DNA but not RNA (Figure 2E-G). It is notable that, in MEFs, the transcription of other type 1 IFNs, type III IFNs and anti-inflammatory cytokines such as $/ / 4$ and $/ / 10$ was not observed in response to DNA stimulation (data not shown). Defects in the production of cytokines in response to DNA were found in transformed MEFs lacking $\mathrm{Ku} 80\left(\mathrm{Xrcc5}^{-/-}\right)$(Figure $\left.2 \mathrm{H}\right)$ or $\mathrm{Ku} 70\left(\mathrm{Xrcc6}^{-/-}\right)$(not shown) and the transcription of Ifnb in response to DNA was also impaired in primary adult murine skin fibroblasts lacking both Ku genes (Figure 2I) indicating that this phenotype requires both $\mathrm{Ku}$ and DNA-PKcs and is not restricted to embryonic cells. Finally, the re-expression of $\mathrm{Ku} 80$ in $\mathrm{Xrcc5}^{-1-}$ cells restored their DNA-dependent production of $\mathrm{Cxcl} 10$ to wild-type levels (Figure 2J). Collectively, these data indicate that DNA-PK acts as a DNA sensor by binding foreign DNA in the cytoplasm and activating a host innate immune response.

\section{DNA-PK activates IRF-3 dependent innate immune responses}

We delimitated the signalling pathway downstream of DNA-PK by using various MEFs lacking specific signalling components. In Irf3 ${ }^{-/-}$cells the increase in transcription of Ifnb, Cxcl10, II6 and Isg54 (an IRF-3-dependent gene (Navarro et al., 1998)) in response to DNA was lost (Figure 3A). Equally,

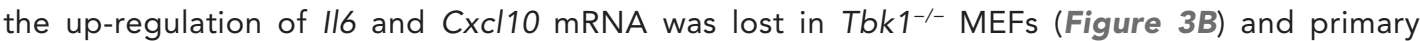
Tmem173-- MEFs (data not shown). Similar results have been reported previously (Stetson and Medzhitov, 2006; Ishii et al., 2006; Ishikawa et al., 2009) and in a similar manner confirmed that cytoplasmic DNA sensing in fibroblasts is independent of TLRs (Ishii et al., 2006), IPS-1 (Kumar et al., 2006) (and hence both dsRNA-sensing pathways (Kumar et al., 2006) and RNA-pol III-dependent DNA sensing (Ablasser et al., 2009; Chiu et al., 2009)), and DAl (Ishii et al., 2008; Wang et al., 2008),

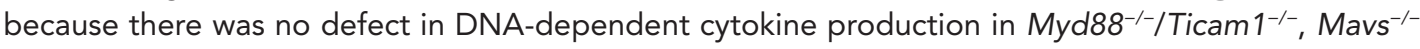
or $\mathrm{Zbp}^{-1-} \mathrm{MEFs}$ (data not shown).

To establish whether DNA-PK acts upstream of IRF-3 activation, we monitored IRF-3 translocation in response to DNA and RNA stimulation. In Prkdc/- MEFs IRF-3 translocation in response to DNA, but not to RNA, was abrogated (Figure 4A) and we obtained similar results in $\mathrm{Xrcc5}^{-1-} \mathrm{MEFs}$ (Figure 4B). In contrast, translocation into the nucleus of the $\mathrm{p} 65$ component of NF-kB, was unaffected by absence of the Prkdc gene (Figure $4 \mathrm{C}$ ). To confirm the activity of IRF-3 and NF-KB at the transcriptional 


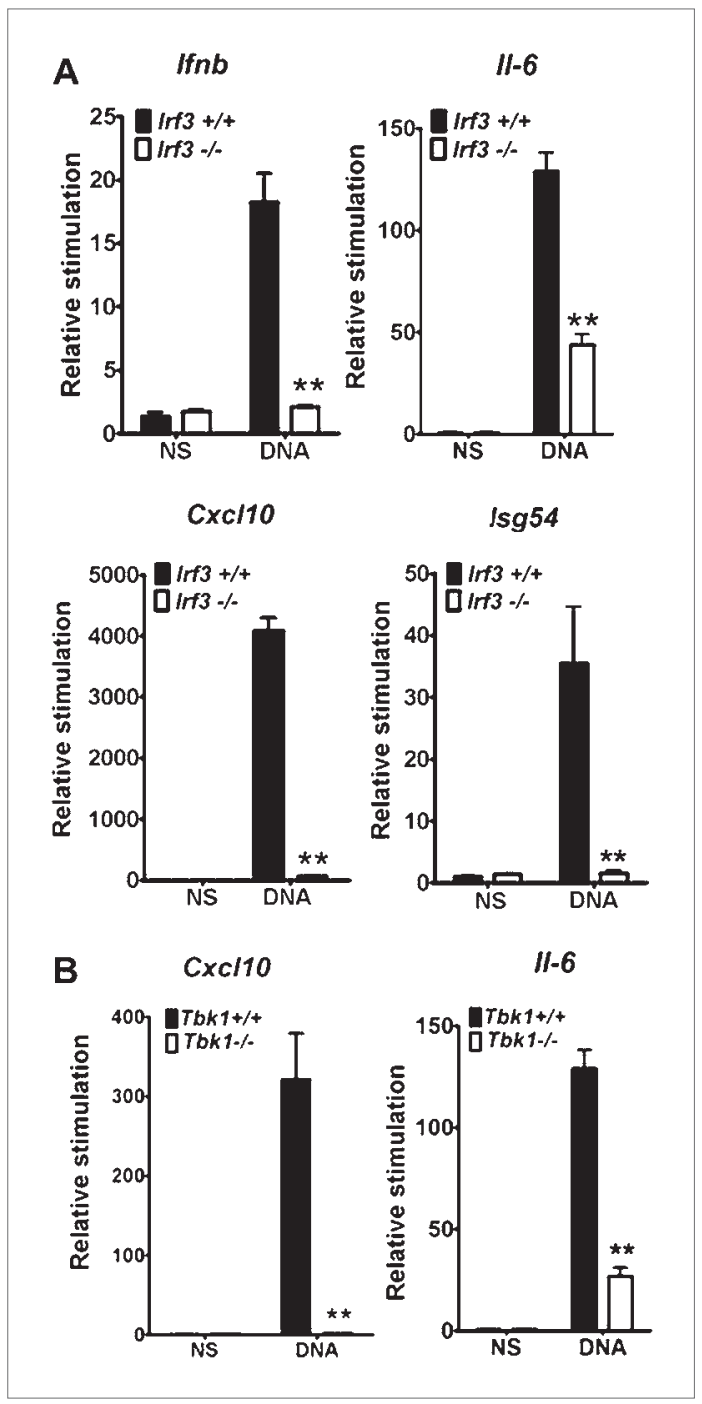

Figure 3. IRF-3 and TBK1 are required for the stimulation of multiple genes in response to DNA. (A) Primary wild type or Irf3-- MEFs were transfected with DNA and the level of induction of Ifnb, II6, Cxcl10 and Isg54 mRNAs were measured by qRT-PCR 6 hr later. (B) Immortalised wild type or Tbk1 $1^{-1-}$ MEFs were transfected with DNA or poly $(I: C)$ and the level of induction of $\|-6$ and $C x C l 10$ was measured by qRT-PCR 6 hr later. (B) *** $p<0.001$, ** $\mathrm{p}<0.01, \mathrm{n}=3$, error bars $\pm \mathrm{SEM}$, ns; non-stimulated. DOI: 10.7554/eLife.00047.005 level we examined induction of the IFN-inducible gene Isg54 (Navarro et al., 1998), which is entirely dependent on IRF-3 activity following DNA stimulation (Figure 3A). We also assayed expression of Nfkbia, a known NF-KB-dependent gene that encodes the IKBa protein (Rupec et al., 1999). Induction of Isg54, but not Nfkbia, was impaired in Prkdc ${ }^{-/}$MEFs in response to DNA but not RNA transfection (Figure 4D). These data confirm the DNA-specific defect in IRF-3, but not NF-KB, activation in cells lacking DNAPKcs and demonstrate that DNA-PK acts as a DNA sensor upstream of the IRF-3-dependent innate immune response. Our data also imply that the existence of an additional DNA sensing pathway in MEFs that is independent of DNA-PK and capable of activating NF-KB.

\section{DNA-PK activates IRF-3 signalling independent of kinase activity}

Previously, DNA-PK was shown to interact directly with IRF-3 (Karpova et al., 2002). We confirmed this interaction by co-immunoprecipitation of both proteins (data not shown). In the study of Karpova et al. (2002) DNA-PKcs was shown to phosphorylate IRF-3 at its N terminus, so enhancing its nuclear retention (Karpova et al., 2002). To test whether phosphorylation of IRF-3 is necessary for the DNA-sensing function of DNA-PK, two approaches were taken. First, we tested Prkdc ${ }^{S C I D}$ MEFs, which express a kinase-dead form of the DNA-PKcs protein lacking its $C$ terminal 83 amino-acids (Blunt et al., 1996; GuimarãesCosta et al., 2009), for their ability to produce Ifnb, Cxcl10 and II-6 in response to DNA or RNA. However, Prkdc ${ }^{S C I D}$ MEFs showed no defect in induction of Ifnb (Figure 5A), II-6 (Figure 5B), and $\mathrm{CxCl} 10$ (Figure $5 \mathrm{C}$ ) in response to either DNA or RNA stimulation. Second, we used the DNAPKcs-specific inhibitor NU7026 (Veuger et al., 2003) to inhibit DNA-PKcs kinase activity in wild type MEFs. Cells treated with NU7026 showed no impairment in production of $\mathrm{CxCl10}$ in response to DNA transfection (Figure 5D). Hence, the kinase activity of DNA-PKcs is not required for activation of IRF-3 in response to DNA.

The finding that the kinase activity of DNA-PKcs was not necessary for DNA sensing prompted an investigation of other interactions with signalling components. To do this we developed an inducible system to study the DNA sensing signalling pathway. HEK293 cells do not activate IRF3 in response to DNA stimulation due to a defect in STING, but by introducing an inducible version of STING into these cells, and then inducing STING expression with doxycycline, the cells activate IRF-3 as shown by its phosphorylation (Figure 5E) and produce cytokines (not shown) in response to double stranded ISD DNA concatamers. Using this system, immunoprecipitation showed that prior to DNA stimulation, STING exists in a complex with Ku70 but this interaction is abrogated following transfection of DNA (Figure 5F). These data suggest that DNA-PK interacts with the STING-dependent signalling pathway and this changes upon DNA activation. 


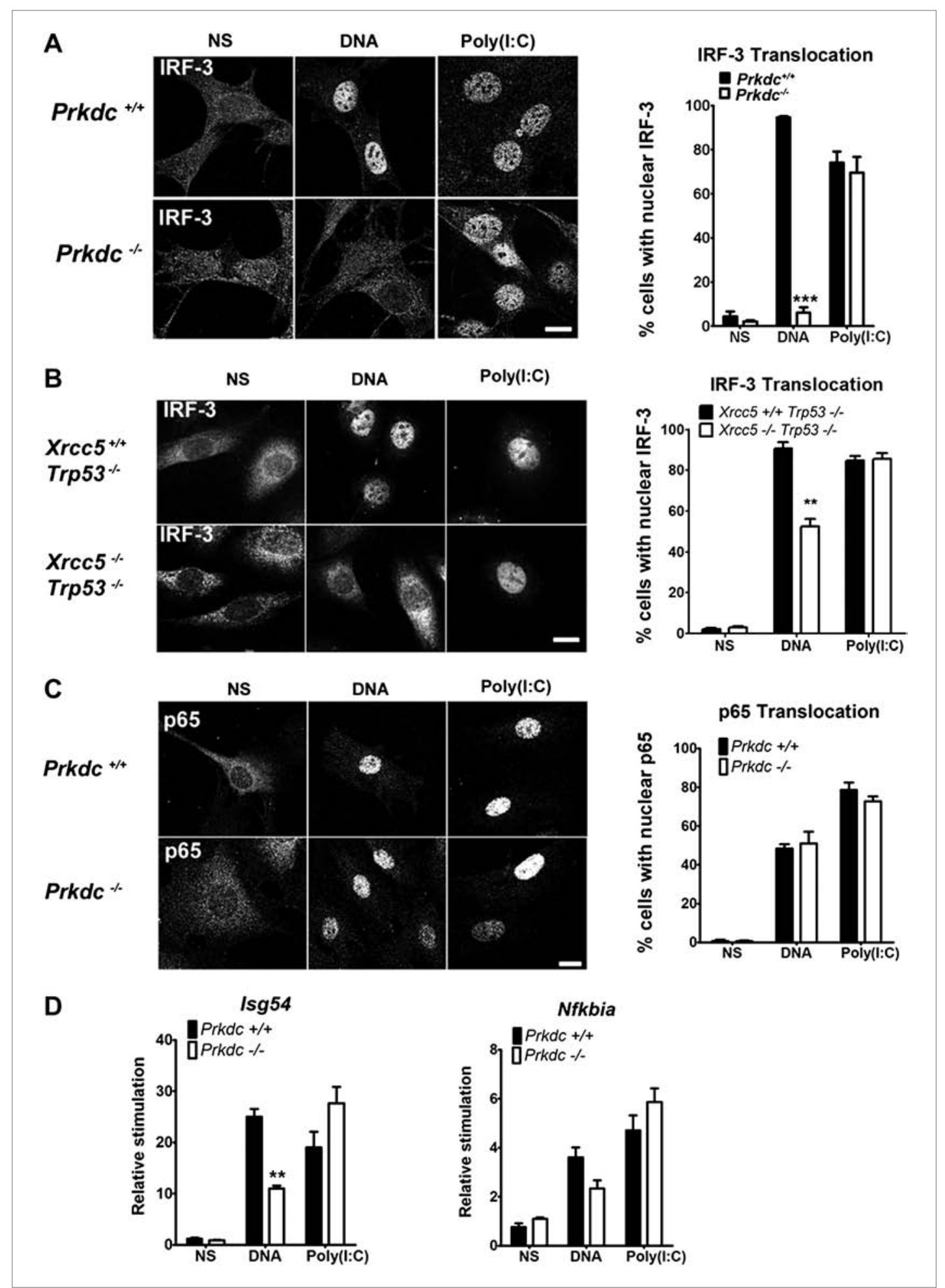

Figure 4. DNA-PK activates IRF-3-dependent, NF-KB-independent signalling. (A) The localisation of endogenous IRF-3 was analysed by immunofluorescence $1 \mathrm{hr}$ after transfection of primary wild type or Prkdc ${ }^{-1-}$ MEFs with DNA or poly (l:C) (left panels) and quantified by scoring cells with nuclear staining (right panels, $n=3$, counts of at least 50 nuclei per slide in randomised fields of view). (B) As (A) but with $\mathrm{Xrcc5}^{+/+} / \operatorname{Trp} 53^{-/-}$and $\mathrm{Xrcc5} 5^{-1-/ T r p 53^{-/-}} \mathrm{MEFs}$ (C) Analysis of p65 translocation in wild type and Prkdc/- MEFs carried out as in (A). (D) Primary wild type or Prkdc ${ }^{-/-}$ MEFs were transfected with DNA or poly (I:C) and the level of induction of Isg54 and Nfkbia were measured by qRT-PCR 6 hr later. ${ }^{* \star} p<0.01,{ }^{\star} p<0.05, n=3$, error bars \pm SEM. ns; non-stimulated. Scale bar; $10 \mu m$. 
A

Ifnb

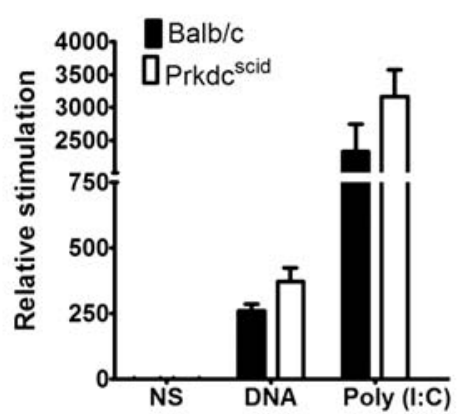

C

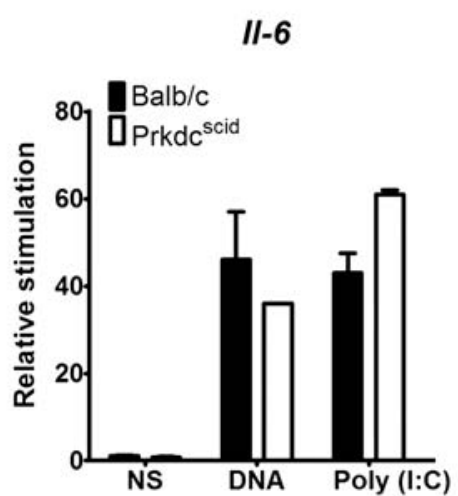

E

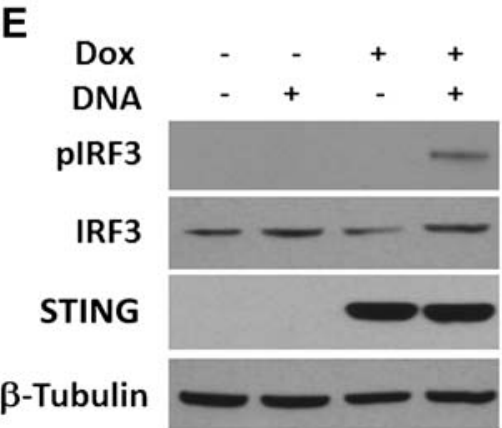

B Cxcl10

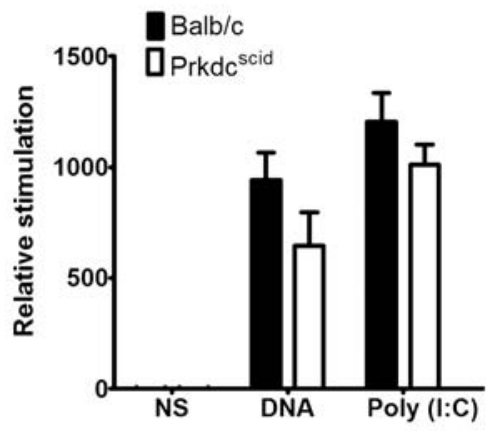

D

CXCL10

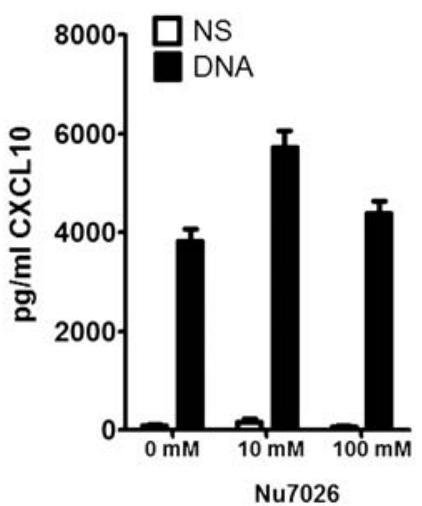

$\mathbf{F}$

DNA (h) $0 \begin{array}{lllll}0 & 6 & 0 & 3 & 6\end{array}$

Dox

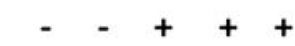

IP (FLAG)

Ku70

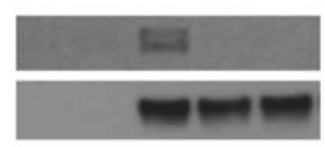

WCL $\mid \begin{aligned} & \text { Ku70 } \\ & \text { STING }\end{aligned}$

Figure 5. DNA-PKcs kinase activity is dispensable for the innate immune response to DNA. Primary fibroblasts from Balb/c or Prkdc ${ }^{S C I D}$ mice were transfected with DNA or poly $(I: C)$ or infected with MVA or NDV and the level of induction of (A) Ifnb, (B) Cxcl10, or (C) II-6 was measured 6 hr later by qRT-PCR. (D) Fibroblasts were incubated with the indicated dose of DNA-PKcs kinase inhibitor, Nu7026, or carrier control and then stimulated with $10 \mu \mathrm{g} / \mathrm{ml}$ DNA. Cxcl10 was measured by ELISA in the supernatants $24 \mathrm{hr}$ following stimulation. $\mathrm{n}=3$, error bars \pm SEM (E). Hek293 Trex cells were stably transfected with FLAG-tagged STING under the control of a doxycyclineinducible promoter. STING expression was induced by addition of doxycycline (Dox, $2 \mu \mathrm{g} / \mathrm{ml}$ ) for $24 \mathrm{hr}$ and cells were stimulated by transfection with $5 \mu \mathrm{g} / \mathrm{ml}$ DNA for $6 \mathrm{hr}$. Protein lysates were then immunoblotted with the indicated antibodies. (F) STING-293Trex cells were induced to express STING by addition of doxycycline (Dox, $2 \mu \mathrm{g} / \mathrm{ml}$ ) for $24 \mathrm{hr}$ and stimulated with $5 \mu \mathrm{g} / \mathrm{ml}$ DNA for the indicated times. STING was then immunoprecipitated and whole cell lystes (WCL) or precipitated proteins (IP) were immunoblotted using the indicated antibodies. DOI: 10.7554/eLife.00047.007

DNA-PK contributes to the innate immune response to VACV in MEFs

We tested the relevance of this novel DNA-PK-dependent DNA sensing mechanism to virus infection using VACV strain modified virus Ankara (MVA). MVA activates innate immunity via TLR-dependent and independent pathways (Delaloye et al., 2009) and, during infection, VACV DNA accumulates in 


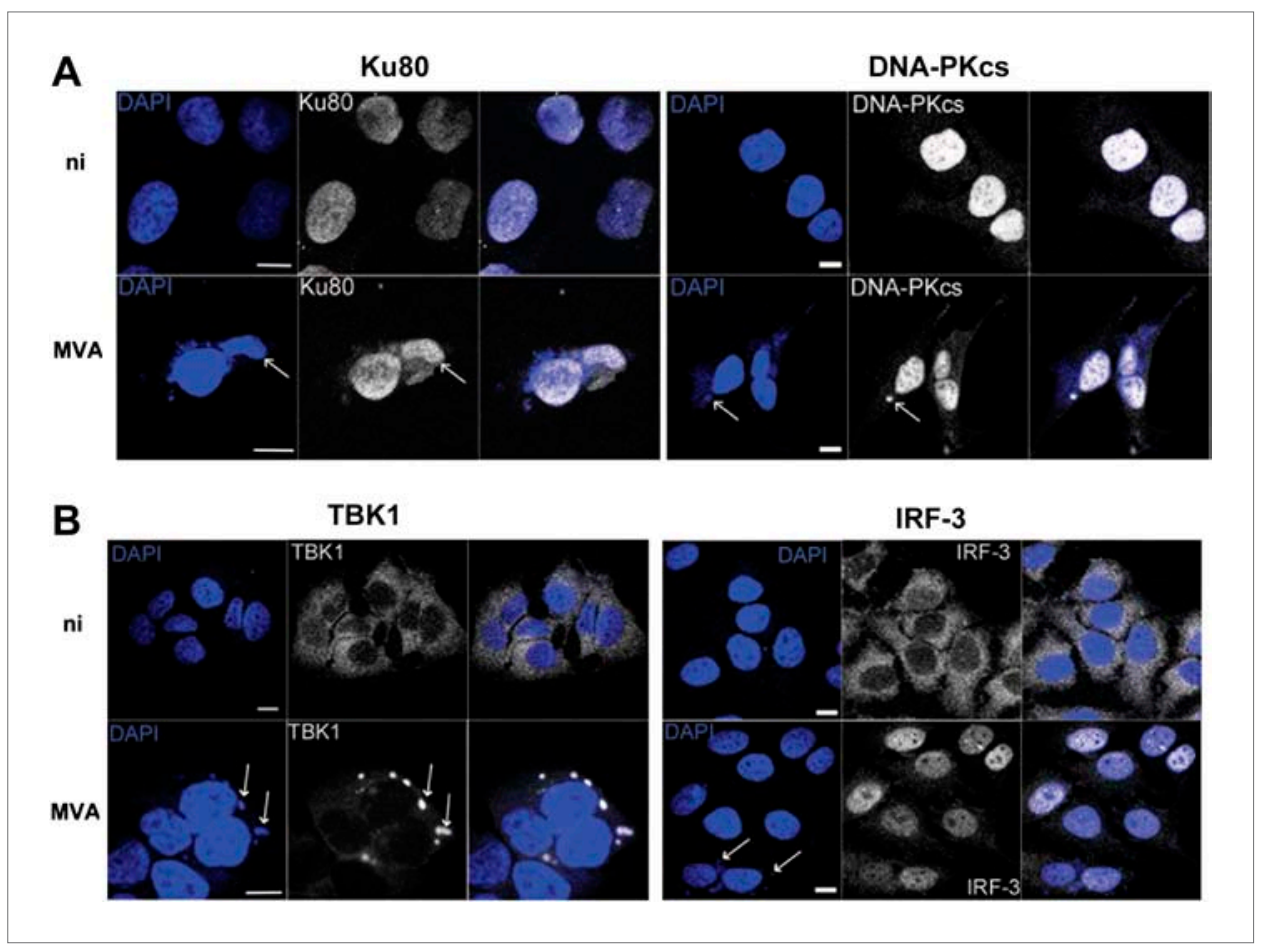

Figure 6. DNA-PK and TBK1 localise to sites of VACV DNA replication in infected cells. HeLa cells were untreated or infected with MVA (m.o.i. = 5) for 6 hr. Cells were then fixed and stained with antibodies against $(\mathbf{A})$ Ku80 or DNA-PKCS, and (B) TBK1 or IRF-3. Cytoplasmic viral factories formed after MVA infection are visualised with DAPI (blue). Sites of co-localisation of DNA-PKcs or Ku80 with viral factories are indicated by white arrows. Scale bars; $10 \mu \mathrm{m}$. ni; non-infected. DOI: 10.7554/eLife.00047.008

cytoplasmic virus factories in association with many virus proteins (Moss, 2007). We reasoned that such large aggregates of foreign DNA, present in a cellular compartment where DNA does not normally reside, would present an excellent target for an innate immune DNA-sensing mechanism. By $6 \mathrm{hr}$ post infection, both Ku80 and DNA-PKcs had accumulated in these viral factories (Figure 6A) together with the IRF-3-activating kinase TBK1 (Figure 6B, left panel), consistent with its role in this sensing pathway, although IRF-3 was mostly nuclear, reflecting its activation by virus infection (Figure 6B, right panel).

In fibroblasts, MVA induces an IRF-3-dependent response (Figure 7A) which is independent of TLR signalling, RNA sensing (and hence RNA-pol III-dependent DNA sensing) and DAI (data not shown), indicating that viral genomic DNA is a major target for the host response to VACV infection. We found the production of $\mathrm{CxCl} 10$ and II-6 was strongly impaired in cells lacking Prkdc ${ }^{-/-}$or $\mathrm{Xrcc5}^{-/}$during MVA infection (Figure 7B,C) whereas the response of these cells to infection by Newcastle disease virus (NDV, an RNA virus) remained intact (Figure 7B,C). Isg54, but not Nfkbia, transcription was impaired in response to MVA infection in Prkdc ${ }^{-/}$MEFs, whilst the response of both genes to NDV was equivalent (Figure 7D), directly indicating that the DNA-PKcs-dependent activation of IRF-3 is important in the response to DNA virus infection. Additionally, in primary Prkdc ${ }^{-1-}$ MEFs, there was greater MVA protein synthesis 4-8 hr post infection (Figure 7E), not only re-enforcing the function of DNA-PKcs in the anti-viral response but also showing the failure to respond to DNA in Prkdc ${ }^{-/-} \mathrm{MEFs}$ is not due to a failure to infect these cells or synthesise viral macromolecules. These data provide direct evidence that the innate immune response to infection by a DNA virus is regulated by DNA-PK and confirm the role of this complex in cytoplasmic DNA sensing in the context of infection.

\section{DNA-PK activates the innate immune response to DNA in vivo}

To confirm that DNA-PK-dependent DNA sensing contributes to the innate immune response in vivo, we transfected nucleic acids directly into the ear pinnae of mice and assayed the induction of 


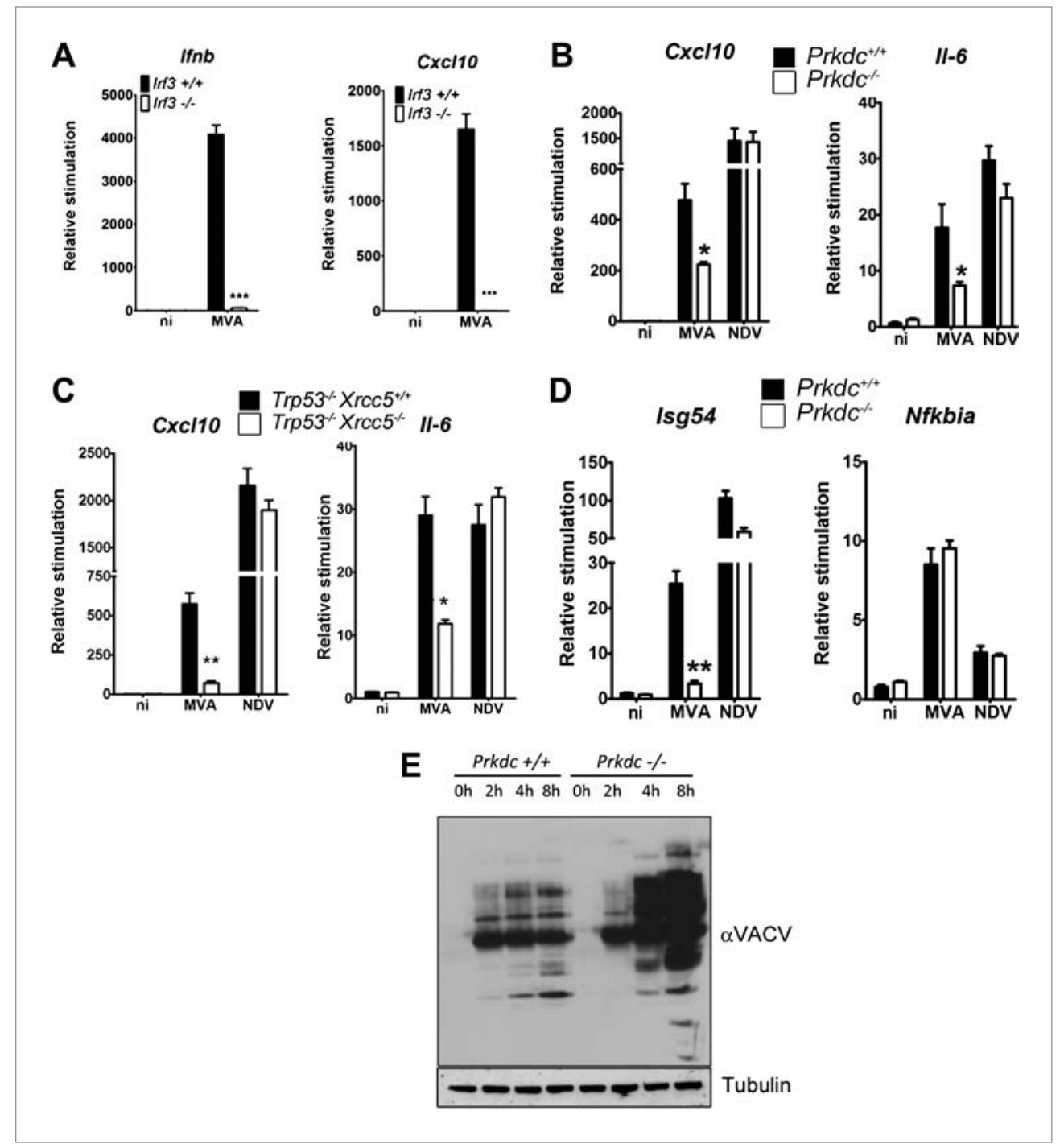

Figure 7. DNA-PK contributes to the IRF-3-dependent innate immune response to MVA. (A) Ifnb and Cxcl10 transcription was measured $6 \mathrm{hr}$ following MVA infection of primary WT and Irf3-1- fibroblasts at an m.o.i. of 5 . (B) Wild type and Prkdc ${ }^{-1-}$ MEFs were infected with MVA or NDV and the level of induction of Cxcl10 and II-6 were measured $6 \mathrm{hr}$ later by qRT-PCR. (C) As (A) but with immortalised Xrcc5 $5^{+/} / \mathrm{Trp} 53^{-1-}$ and $\mathrm{Xrcc5} 5^{-1-} / \mathrm{Trp} 53^{-/-} \mathrm{MEFs}$. (D) The induction of Isg54 and Nfkbia mRNA was measured by qRT-PCR 6 hr after MVA or NDV infection of wild type and Prkdc ${ }^{-/-}$cells. (E) Expression of VACV proteins, analysed by immunoblotting with a rabbit polyclonal anti-VACV serum, at the indicated times following infection of primary Prkdc ${ }^{+/+}$and Prkdc $^{-1-}$ MEFs with MVA (m.o.i. $=5$ ). ${ }^{\star \star \star} p<0.001,{ }^{\star \star} p<0.01,{ }^{*} p<0.05, n=3$, error bars $\pm S E M$, ni; non-infected. DOI: 10.7554/eLife.00047.009

innate immune transcriptional responses by qPCR analysis of extracted RNA $12 \mathrm{hr}$ later. DNA transfection induced both Ifnb and $/ 16$ and this was significantly reduced in Prkdc ${ }^{-1-}$ mice. By contrast, both WT and Prkdc ${ }^{-1-}$ mice exhibited equivalent responses to poly(l:C) (Figure 8A). Hence, DNA-PKcs plays a key role in potentiating the innate immune response to ectopic DNA in vivo. We next infected WT and Prkdc $^{-1-}$ mice with either the DNA virus MVA or with influenza virus (an RNA virus), and assayed expression of Ifnb and $1 / 612 \mathrm{hr}$ later. The absence of DNA-PK severely impaired induction of Ifnb and $1 / 6$ in response to MVA but not to influenza virus (Figure 8B). Similarly, Prkdc ${ }^{-1-}$ mice exhibited severe impairment of 116 induction in response to HSV-1 (Figure $8 \mathrm{C}$ ): no Ifnb induction could be detected in this experiment. Overall these data confirm that the innate immune response to DNA viruses immediately after infection is significantly dependent upon DNA-PK, despite the presence of other DNA sensors reported hitherto. 


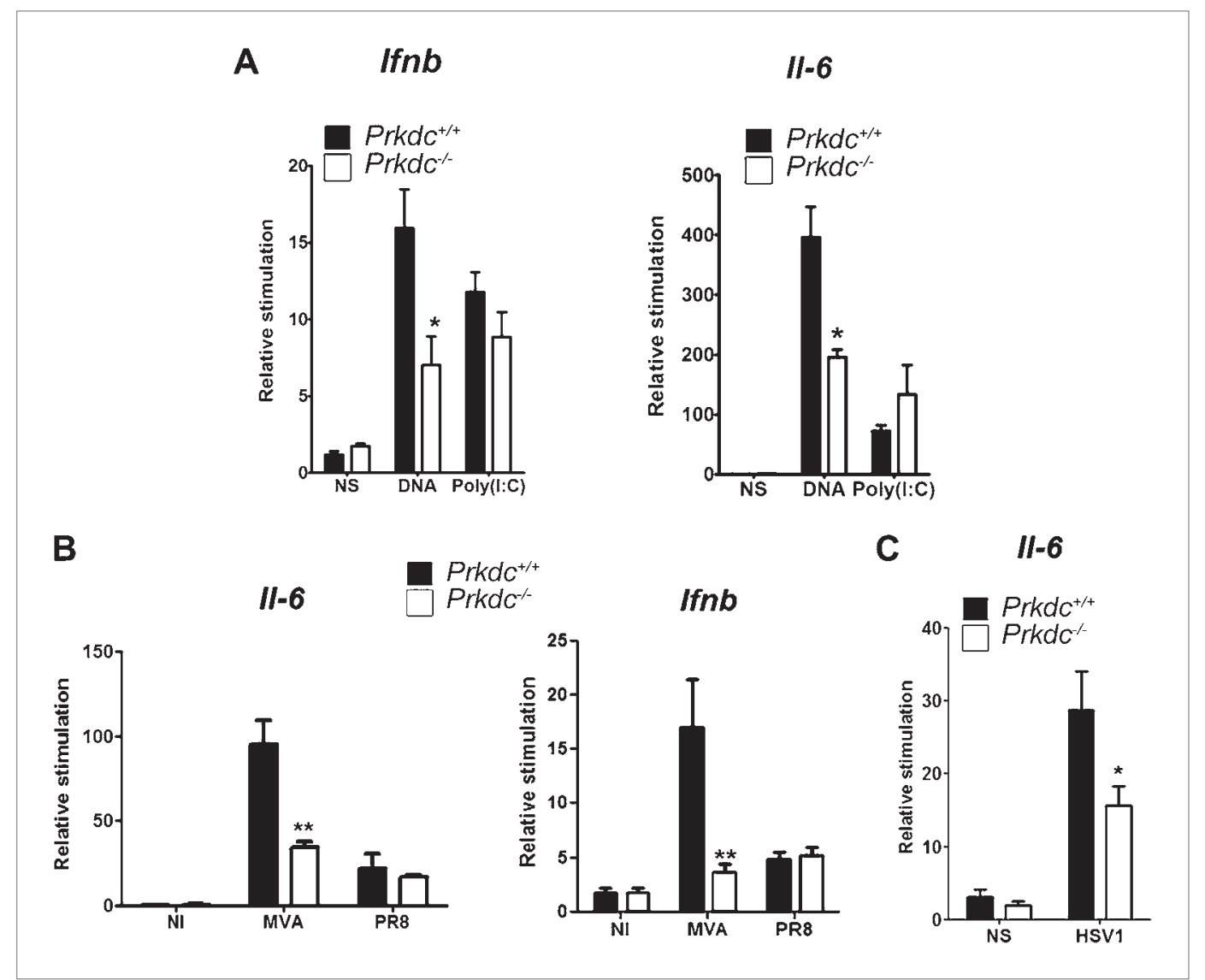

Figure 8. DNA-PKcs contributes to the innate immune response to MVA, HSV-1 and DNA in vivo. (A) Groups of five $\mathrm{Prkdc}^{+/+}$and Prkdc $\mathrm{C}^{-/-}$mice were injected intradermally into the ear pinna with cationic lipids complexed with $1 \mu \mathrm{g}$ DNA or poly(l:C). RNA was extracted from the tissue $12 \mathrm{hr}$ later and Ifnb and $1 / 6$ transcription was measured by qPCR. (B) Groups of five Prkdc ${ }^{+/+}$and Prkdc $c^{-/-}$mice were infected intradermally with $10^{6}$ pfu of MVA or influenza virus strain A/PR/8/34 (PR8) and $12 \mathrm{hr}$ later Ifnb and $1 / 6$ transcription was measured by qPCR from RNA extracted from the local site of infection. (C) As (B) but with HSV-1 strain S17. Note that levels of ifnb could not be measured above background in this experiment. ${ }^{\star} p<0.1,{ }^{\star \star} p<0.01, n=5$, error bars $\pm S E M$, ni; non-infected. DOI: 10.7554/eLife.00047.010

\section{Discussion}

The identification of DNA-PK as a DNA sensor advances understanding of the innate immune response to infection and expands the current repertoire of DNA sensing mechanisms. In this study we show that the three proteins which constitute the DNA-PK complex; Ku70, Ku80 and DNA-PKcs, bind in significant amounts to DNA transfected into the cytoplasm of resting cells leading to an IRF-3dependent innate immune response. Consistent with this, we found DNA-PK and TBK1 localised to sites of DNA replication during virus infection. Previous studies have ruled out a role for DNA-PK in the production of Ifnb in response to DNA in monocytic cells (Stetson and Medzhitov, 2006) and HEK293 cells (Zhang et alo, 2011a). However, although DNA-PK components are expressed at high levels in a wide range of tissues and cell types, they are absent in primary macrophages ((Moll et al., 1999) and data not shown), and we now show that in fibroblasts and in mice the innate immune response to DNA and DNA viruses is dependent on DNA-PKcs. The in vivo deficiency in DNA sensing in the absence of DNA-PKcs is observed despite the presumed presence of other DNA sensors. The observation that this defect is not extended to RNA, LPS or to RNA viruses shows that DNA-PK loss does not confer a general defect on intracellular innate immune signalling, and the same is true in cultured Prkdc ${ }^{-1-}$ MEFs which respond normally to RNA. It was noticed that the defect in the innate immune response to DNA was greater in cells lacking DNA-PKcs than in cells lacking Ku, even though $\mathrm{Ku}$ can still bind DNA in the absence of DNA-PKcs. This suggests that signalling can progress with 
DNA-PKcs interacting with DNA in the absence of Ku but that Ku enhances the signalling process by increasing the affinity of the protein complex for DNA. The phenotypic defect in DNA sensing was consistent in cells from four separate genotypes, ruling out the possibility that it was caused by a second site mutation. Consistent with this reintroduction of Ku80 into $\mathrm{Xrcc5}^{-/-}$cells restored DNA sensing (Figure 2J).

The well-studied Prkdc SCID mutation kills the kinase activity of DNA-PKcs via the introduction of a premature stop codon that results in expression of a truncated protein (Blunt et al., 1996). Although kinase activity is essential for DNA-PKcs to function in DNA repair, and therefore V(D)J recombination, this mutation did not affect the ability of DNA-PK to function as an innate immune DNA sensor. The functional significance of the interaction of DNA-PK with IRF-3 and its subsequent N-terminal phosphorylation reported by Karpova et al. (2002) remains unknown. However, we show here that Ku interacts with STING in resting cells and that this interaction is abrogated upon DNA stimulation (Figure 5F). In the future, further work is necessary to understand how TBK-1 and STING contribute to the full activation of IRF-3 following binding of DNA to DNA-PK to allow IRF-3 translocation to occur.

DNA can act as a powerful immunostimulatory agent in many contexts. DNA vaccination relies on DNA sensing to invoke a powerful innate immune response that, in turn, assists the adaptive response (Ishii et al., 2008). Understanding how to optimise such vaccines, therefore, relies on understanding the mechanisms of detection of DNA by the immune system. Furthermore, one of the most common vaccine adjuvants, alum, acts by stimulating the release of DNA from neutrophils (Zhang et al., 2011b). Neutrophil extracellular traps (NETs) consist of webs of DNA with globular proteins, are released by a specific form of cell death (Fuchs et al., 2007) and function as antimicrobial traps, thereby contributing to the innate immune response (Brinkmann et al., 2004).

Outside the context of infection, DNA can act as a damage-associated molecular pattern (DAMP), accelerating inflammatory responses following its release from dying or damaged cells directly contributing to the pathogenesis of various diseases such as atherosclerosis (Oka et al., 2012) and deep vein thrombosis (Brill et al., 2012). The ability of DNA to act as a DAMP may also link nucleic acid sensing to several autoimmune disorders. In general, autoimmune conditions are characterised by immune responses against host molecules and tissues and are frequently associated with inflammation. Although the causative factors of many such conditions are incompletely understood, it is clear that deregulation of immune signalling may lead to autoinflammation and autoimmunity in some instances (Rioux and Abbas, 2005). Indeed, the accumulation of DNA and its subsequent detection by DNA sensing pathways can result in the initiation of autoimmune diseases. Mice which lack either of two enzymes responsible for degradation of DNA, 3' repair exonuclease 1 (Trex1) and DNasell, develop spontaneous autoimmune disorders associated with the initiation of IRF-3-dependent cytosolic DNA sensing (Kawane et al., 2006; Stetson et al., 2008; Okabe et al., 2008). The absence of DNasell results in chronic polyarthritis which is thought to be a result of the inflammation caused by a lack of clearance of DNA from macrophages (Kawane et al., 2006; Okabe et al., 2008). Trex1 deficiency or mutation, on the other hand, is associated with systemic lupus erythematosus (SLE), chilblain lupus and the human disease Aicardi-Goutières syndrome (AGS) (Lee-Kirsch et al., 2007a, 2007b; Stetson et al., 2008) and in this case inflammation is initiated from non-haematopoietic cells via a STING-dependent pathway (Gall et al., 2012). Interestingly, defects in the clearance of NETs have also been suggested to contribute to the initiation of SLE (Hakkim et al., 2010). Furthermore, the up-regulation of the inflammasome-activating DNA sensor absent in melanoma 2 (AIM2) in a mouse model of lupus and in patients with SLE-associated nephritis (Roberts et al., 2009; Kimkong et al., 2009) and the presence of anti-DNA-PK and anti-RNA-Pol III antibodies in patients with SLE and systemic sclerosis (Cavazzana et al., 2008, 2009) makes the link between DNA sensing and autoimmune disorders worthy of further investigation.

The identification of several candidate DNA sensors in multiple cells types in recent years (Hornung and Latz, 2010) suggests the evolution of redundancy in this system. This redundancy is not surprising given the tendency of pathogens to evolve escape-mechanisms for evading host immune mediators (Versteeg and García-Sastre, 2010; Bardoel and Strijp, 2011) in turn inducing the host to evolve further pathogen recognition mechanisms. In the context of DNA sensing this is exemplified by the relatively recent evolution of the PYHIN domain proteins, such AIM2 and IFI16 (Schattgen and Fitzgerald, 2011), which are a mammalian addition to the ancient innate immune system. Furthermore, a function of DAl was recently uncovered by identifying murine cytomegalovirus protein, vIRA, which 
interacts with DAI and inhibits its ability to initiate DNA-induced necroptosis (Upton et al., 2012). The biological function for DAl may therefore be in the initiation of a cell death pathway, rather than an IRF-3 dependent inflammatory response. This indicates there are at least three outcomes to cytosolic DNA sensing, the induction of cytokine expression via IRF-3 and NF-kB activation, the secretion of IL-1 $\beta$ via the AIM 2 inflammasome and the induction of necroptosis by DAI. What is not clear though, is how these different responses contribute to the overall immune response to infection by DNA pathogens and to what extent they are cell and tissue-type dependent. Further work is necessary to uncover the relative contributions of these different DNA sensing mechanisms in specific cell types and to different DNA structures as well as to understand how these sensors co-ordinate with STING and other adaptor proteins to activate TBK1 and IRF-3 (Paludan et al., 2011; Barber, 2011).

Overall these findings provide a novel function for DNA-PK in the innate immune response, beyond its roles in DNA repair and V(D)J recombination, and increase our understanding of the innate immune response to cytoplasmic DNA.

\section{Materials and methods}

\section{Mice}

Prkdc ${ }^{+/-}$mice on a 129 background were a kind gift from Dr Fred Alt (Gao et al., 1998) and Prkdc ${ }^{S C I D}$ and Balb/c mice were from Harlan laboratories. Animals were maintained as required under UK Home Office regulations. Groups of 5 age and sex matched mice were injected intradermally with $1 \mu \mathrm{g}$ DNA or poly(l:C) (Invivogen, San Diego, CA) pre-incubated with $2 \mu$ Lipofectamine2000 in Optimem (Life Technologies, Grand Island, NY) or injected intradermally with $10^{6}$ plaque forming units (pfu) of MVA, HSV-1 or influenza virus A/PR/8/34 in PBS. Primary mouse embryonic fibroblasts (MEFs) were isolated from E13.5 embryos derived from time-mated pregnant mice using standard protocols.

\section{Cell culture and transfection}

HEK293T and HEK293 Trex cells (Life Technologies, Grand Island, NY) were maintained in DMEM containing $10 \%$ FBS with the addition of blasticidin $(5 \mu \mathrm{g} / \mathrm{ml})$ and zeocin $(100 \mu \mathrm{g} / \mathrm{ml})$ for the selection and maintenance of the inducible STING-expressing cell line (STING-293Trex). MEFs and murine skin fibroblasts (MSFs) from various genetic backgrounds were maintained in DMEM containing 15\% FBS, $100 \mathrm{U} / \mathrm{ml}$ penicillin and $100 \mathrm{\mu g} / \mathrm{ml}$ streptomycin. Primary Prkdc $\mathrm{C}^{++}$and Prkdc ${ }^{-/-}$MEFs were prepared in house on multiple occasions or supplied as a kind gift by Dr Brian Hemmings and were used only at passage 1. Transformed Prkdc ${ }^{-/}$MEFs (used solely for experiments leading to the data presented in Figure 2D) were a kind gift from Professor Penelope Jeggo. HeLa cells were maintained in RPM.I containing 10\% FBS and 2 mM L-glutamine. Transfections were carried out with Fugene6 (Roche, Penzburg, Germany).

\section{DNA concatenation}

Double stranded oligonucleotide DNA, ISD (sense sequence, TACAGATCTACTAGTGATCTATGAC TGATCTGTACATGATCTACA) was phosphorylated at the $5^{\prime}$ end by incubation with T4 polynucleotide kinase (New England Biolabs, Ipswich, MA) for $30 \mathrm{~min}$ at $37^{\circ} \mathrm{C}$ and then ligated with T4 DNA ligase (Promega, Madison, WI) for $16 \mathrm{hr}$ at $15^{\circ} \mathrm{C}$. Concatenation was confirmed by agarose gel electrophoresis. This DNA was used at $10 \mu \mathrm{g} / \mathrm{ml}$ for transfection unless stated otherwise.

\section{Biotinylation}

3' biotinylated oligonucleotides were purchased from IDT DNA Technologies. Other nucleic acids were biotinylated using the Photoprobe biotinylation kit (Vector Labs, Burlingame, CA) following the manufacturer's instructions.

\section{DNA pull down assay}

Concatenated oligonucleotide DNA (sequence as above) that was biotinylated at the 3 ' end was transfected into cells using PEI (Sigma-Aldrich, St Louis, MI). After $30 \mathrm{~min}$, cells were lysed in buffer containing $10 \mathrm{mM}$ Tris- $\mathrm{Cl}, \mathrm{pH} 8,0.1 \% \mathrm{NP} 40,10 \mathrm{mM} \mathrm{MgCl}_{2}$ and the cytoplasmic fraction was isolated by centrifugation at $1500 \mathrm{~g}$ for $3 \mathrm{~min}$. Streptavidin agarose (Thermo Scientific, Rockford, IL), $30 \mu \mathrm{l}$, was incubated with the lysate for $1 \mathrm{hr}$ at $4^{\circ} \mathrm{C}$ and then washed three times in PBS. Purified proteins were analysed by SDS-PAGE and immunoblotting or stained by coomassie-blue and identified by liquid chromatography and tandem mass spectrometry (LC-MS/MS) at the Centre for Systems Biology at Imperial College London. 


\section{Virus infection}

VACV strain MVA was purified from cytoplasmic extracts of infected BHK-21 cells by sedimentation through a cushion of $36 \%$ (wt/vol) sucrose and was titrated by plaque assay on chicken embryo fibroblasts. NDV and influenza virus strain A/PR/8/34 were kind gifts from Prof Wendy Barclay. HSV-1 strain S17, a gift from Dr Colin Crump, was grown in Vero cells and purified on ficoll gradients. These viruses were used for infections for the indicated times and at indicated doses.

\section{Immunodetection and immunoprecipitation}

For immunoblotting, cell lysates were separated by polyacrylamide gel electrophoresis and transferred onto Immobilon P membranes (GE Healthcare, Little Chalfont, UK). The membranes were blocked in $5 \%$ non-fat milk in TBS containing $0.1 \%$ Tween 20 for $1 \mathrm{hr}$ at room temperature. Membranes were probed with antibodies against Ku70 (Abcam, Cambridge, UK), Ku80 (Santa Cruz Biotech, Santa Cruz, CA), DNA-PKcs (Millipore, Billerica, MA), tubulin (Millipore, Billerica, MA), histone H3 (Millipore, Billerica, MA), hIRF-3 (Santa Cruz Biotech, Santa Cruz, CA), p-IRF-3 (serine 396, Abcam, Cambridge, UK), HMGB1 (Abcam, Cambridge, UK), FLAG (Sigma-Aldrich, St Louis, MI) or VACV strain Western Reserve (Law et al., 2006) and bound immunoglobulin was detected with horse-radish peroxidase-linked secondary antibodies (Agilent, Santa Clara, CA). Ku80, IRF-3 (Life Technologies, Grand Island, NY) or control antibodies were used for immunoprecipitation from HeLa cell lysates expressing IRF-3. FLAG-agarose matrix (Sigma-Aldrich, St Louis, MI) was used for immunoprecipitation of STING from STING-293Trex cells. For immunofluorescence, cells were seeded onto $15 \mathrm{~mm}$ glass coverslips, infected with MVA at 5 pfu per cell for $6 \mathrm{hr}$ or transfected and fixed with $4 \%$ paraformaldehyde. Cells were permeabilised with PBS containing $0.2 \%$ Triton-X100 and blocked with $5 \%$ non-fat milk in PBS containing $0.1 \%$ Tween 20 for $1 \mathrm{hr}$ at $20^{\circ} \mathrm{C}$. Incubation with primary antibodies against Ku70 (Abcam, Cambridge, UK), DNA-PKcs (Millipore, Billerica, MA), mIRF-3 (Life Technologies, Grand Island, NY) hIRF-3, p65 (both Santa Cruz Biotech, Santa Cruz, CA) or TBK1 (Cell Signalling, Danvers, MA) diluted in PBS with $1 \%$ milk, for $1 \mathrm{hr}$ at $20^{\circ} \mathrm{C}$ was followed by detection with alexa-fluorconjugated secondary antibodies (Life Technologies, Grand Island, NY). Cells were counterstained with DAPI and mounted with Mowiol. Images were obtained with a Zeiss Pascal 510 confocal microscope and processed with Zeiss LSM software (Zeiss, Oberkochen, Germany). For quantification of translocation or IRF-3 or NF-KB into the nucleus 50 cells were counted in random fields of view, in biological triplicates, for each condition and scored for the presence of nuclear staining.

\section{Enzyme-linked immunosorbent assay (ELISA)}

Levels of $C x c / 10$ and Ifn $\beta$ in cell supernatants were measured using ELISA kits (R\&D systems, Minneapolis, $\mathrm{MN}$ or PBL, Piscataway, NJ, respectively) according to the manufacturer's instructions.

\section{Transcriptional analysis}

Total cellular RNA was extracted using an RNeasy kit (Qiagen, Hilden, Germany). cDNA synthesis was carried out with Superscript III Reverse Transcriptase (Life Technologies, Grand Island, NY) using 500 ng of template RNA. qPCR was performed on a 7900HT series thermocycler (Life Technologies, Grand Island, NY) with Fast SYBR Green Master Mix (Life Technologies, Grand Island, NY). HPRT was used as the reference gene in all assays. Data were analysed with RQ manager 1.2 software (Life Technologies, Grand Island, NY) and presented as a fold increase relative to time zero. Primers for QPCR were as follows:

$$
\begin{aligned}
& \text { Cxcl10 For 5' ACTGCATCCATATCGATGAC 3', } \\
& \text { Cxcl10 Rev 5' TTCATCGTGGCAATGATCTC 3', } \\
& \text { Ifn } \beta \text { For 5' CATCAACTATAAGCAGCTCCA 3', } \\
& \text { Ifn } \beta \text { Rev 5' TTCAAGTGGAGAGCAGTTGAG 3', } \\
& \text { Ccl5 For 5' ACGTCAAGGAGTATTTCTACAC 3', } \\
& \text { Ccl5 Rev 5' GATGTATTCTTGAACCCACT 3', } \\
& \text { II-6 For 5' GTAGCTATGGTACTCCAGAAGAC 3', } \\
& \text { II-6 Rev 5' GTAGCTATGGTACTCCAGAAGAC 3', } \\
& \text { Cxcl2 For 5' GAGCTTGAGTGTGACGCCCCC 3', } \\
& \text { Cxcl2 Rev 5' GTTAGCCTTGCCTTGTCAG 3', } \\
& \text { Ccl3 For 5' ACTGCCTGCTGCTTCTCCTA 3', } \\
& \text { Ccl3 Rev 5' TTGGAGTCAGCGCAGATCTG 3', } \\
& \text { Ccl4 For 5' GCCCTCTCTCTCCTCTTGCT 3', }
\end{aligned}
$$


Ccl4 Rev 5' CTGGTCTCATAGTAATCCATC 3',

Ccl2 For 5' CTTCTGGGCCTGCTGTTCA 3',

Ccl2 Rev 5' CCAGCCTACTCATTGGGATCA3',

Ifny For 5' TCAAGTGGCATAGATGTGGAAGAA3'

Ifny Rev 5' TGGCTCTGCAGGATTTTCATG 3',

II-4 For 5' CATGCACGGAGATGGATG 3',

II-4 Rev 5' ACCTTGGAAGCCCTACAGAC 3',

II-10 For 5' TCCTTAATGCAGGACTTTAAGGGTTACTTG 3',

II-10 Rev 5' GACACCTTGGTCTTGGAGCTTATTAAAATC 3',

HPRT For 5' GTTGGATACAGGCCAGACTTTGTTG 3',

HPRT Rev 5' GATTCAACTTGCGCTCATCTTAGGC 3',

Nfkbia For 5' CTGCAGGCCACCAACTACAA3',

Nfkbia Rev 5' CAGCACCCAAAGTCACCAAGT 3'

Isg54 For $5^{\prime}$ ATGAAGACGGTGCTGAATACTAGTGA 3'

Isg54 Rev 5' TGGTGAGGGCTTTCTTTTTCC 3'

\section{Statistical analysis}

Statistical analysis was carried out using student's t-test with Welch's correction where necessary.

\section{Acknowledgements}

The authors thank Fred Alt for Prkdc ${ }^{+/-}$mice, Paul Hasty for supplying Xrcc5 $5^{-/ / T r p 53^{-/-}}$MEFs and $\mathrm{Xrcc5}^{-/-} \mathrm{Xrcc6}^{-/-}$murine skin fibroblasts, Penelope Jeggo and Brian Hemmings for Prkdc ${ }^{-1-}$ MEFs, Shiuzu Akira for Dai ${ }^{-/-}$and Myd88/Trif-/- MEFs, Felix Randow for Tbk1 1/- MEFs, Glen Barber for Sting ${ }^{-/-}$MEFs, Kate Fitzgerald for Irf3-/- and Mavs ${ }^{-/-}$MEFs, Wendy Barclay for NDV and influenza strain A/PR/8/34 and Colin Crump for HSV-1 strain S17. We thank Christian Ku for the production of the STING-293Trex cell line. Mass spectrometry was carried out by Dr Paul Hitchen at Imperial College Centre for Systems Biology. GLS is a Wellcome Trust Principal Research Fellow.

\section{Additional information}

Funding

\begin{tabular}{lll} 
Funder & $\begin{array}{l}\text { Grant reference } \\
\text { number }\end{array}$ & Author \\
\hline Wellcome Trust & 090315 & Geoffrey L Smith \\
\hline Medical Research Council & G1000207 & Geoffrey L Smith \\
\hline Medical Research Council & G0800101 & Nicholas E Peters \\
\hline $\begin{array}{l}\text { Imperial College London } \\
\text { Junior Research Fellowship }\end{array}$ & JRF2009 & Brian J Ferguson \\
\hline $\begin{array}{l}\text { Conselho nacional } \\
\text { de Desenvolvimento Cientifico } \\
\text { e Tecnologico, CNPq/Brasil }\end{array}$ & 210239/2006-9 & \\
\hline
\end{tabular}

The funders had no role in study design, data collection and interpretation, or the decision to submit the work for publication.

Author contributions

BJF, Conception and design, Acquisition of data, Analysis and interpretation of data, Drafting or revising the article; DSM, Conception and design, Acquisition of data, Analysis and interpretation of data, Drafting or revising the article; NEP, Conception and design, Acquisition of data, Analysis and interpretation of data, Drafting or revising the article; HR, Acquisition of data, Analysis and interpretation of data; GLS, Conception and design, Analysis and interpretation of data, Drafting or revising the article

Ethics

Animal experimentation: This work was done with approval from the Home Office of the UK Government under project licence 80/7116. 


\section{References}

Ablasser A, Bauernfeind F, Hartmann G, Latz E, Fitzgerald KA, Hornung V. 2009. RIG-I-dependent sensing of poly $(\mathrm{dA}: \mathrm{dT})$ through the induction of an RNA polymerase III-transcribed RNA intermediate. Nat Immunol 10:1065-72.

Akira S, Uematsu S, Takeuchi O. 2006. Pathogen recognition and innate immunity. Cell 124:783-801.

Balazs AB, Chen J, Hong CM, Rao DS, Yang L, Baltimore D. 2012. Antibody-based protection against HIV infection by vectored immunoprophylaxis. Nature 481:81-4.

Barber GN. 2011. Cytoplasmic DNA innate immune pathways. Immunol Rev 243:99-108.

Bardoel BW, Strijp JA. 2011. Molecular battle between host and bacterium: recognition in innate immunity. J Mol Recognit 24:1077-86. doi: 10.1002/jmr.1156.

Blunt T, Gell D, Fox M, Taccioli GE, Lehmann AR, Jackson SP, et al. 1996. Identification of a nonsense mutation in the carboxyl-terminal region of DNA-dependent protein kinase catalytic subunit in the scid mouse. Proc Natl Acad Sci USA 93:10285-90.

Brill A, Fuchs TA, Savchenko AS, Thomas GM, Martinod K, De Meyer SF, et al. 2012. Neutrophil extracellular traps promote deep vein thrombosis in mice. J Thromb Haemost 10:136-44.

Brinkmann V, Reichard U, Goosmann C, Fauler B, Uhlemann Y, Weiss DS, et al. 2004. Neutrophil extracellular traps kill bacteria. Science 303:1532-5.

Cavazzana I, Ceribelli A, Quinzanini M, Scarsi M, Airo P, Cattaneo R, et al. 2008. Prevalence and clinical associations of anti-Ku antibodies in systemic autoimmune diseases. Lupus 17:727-32.

Cavazzana I, Angela C, Paolo A, Stefania Z, Angela T, Franco F. 2009. Anti-RNA polymerase III antibodies: a marker of systemic sclerosis with rapid onset and skin thickening progression. Autoimmun Rev 8:580-4.

Chiu YH, Macmillan JB, Chen ZJ. 2009. RNA polymerase III detects cytosolic DNA and induces type I interferons through the RIG-I pathway. Cell 138:576-91.

Delaloye J, Roger T, Steiner-Tardivel QG, Le Roy D, Knaup Reymond M, Akira S, et al. 2009. Innate immune sensing of modified vaccinia virus Ankara (MVA) is mediated by TLR2-TLR6, MDA-5 and the NALP3 inflammasome. PLoS Pathog 5:e1000480.

Fuchs TA, Abed U, Goosmann C, Hurwitz R, Schulze I, Wahn V, et al. 2007. Novel cell death program leads to neutrophil extracellular traps. J Cell Biol 176:231-41.

Gall A, Treuting P, Elkon KB, Loo YM, Gale M Jnr, Barber GN, et al. 2012. Autoimmunity initiates in nonhematopoietic cells and progresses via lymphocytes in an interferon-dependent autoimmune disease. Immunity 36:120-31.

Gao Y, Chaudhuri J, Zhu C, Davidson L, Weaver DT, Alt FW. 1998. A targeted DNA-PKcs-null mutation reveals DNA-PK-independent functions for KU in V(D)J recombination. Immunity 9:367-76.

Gu Y, Jin S, Gao Y, Weaver DT, Alt FW. 1997. Ku70-deficient embryonic stem cells have increased ionizing radiosensitivity, defective DNA end-binding activity, and inability to support V(D)J recombination. Proc Natl Acad Sci USA 94:8076-81.

Guimarães-Costa AB, Nascimento MT, Froment GS, Soares RP, Morgado FN, Conceição-Silva F, et al. 2009. Leishmania amazonensis promastigotes induce and are killed by neutrophil extracellular traps. Proc Natl Acad Sci USA 106:6748-53.

Hakkim A, Furnrohr BG, Amann K, Laube B, Abed UA, Brinkmann V, et al. 2010. Impairment of neutrophil extracellular trap degradation is associated with lupus nephritis. Proc Natl Acad Sci USA 107:9813-8.

Hammarsten O, Chu G. 1998. DNA-dependent protein kinase: DNA binding and activation in the absence of Ku. Proc Natl Acad Sci USA 95:525-30.

Hornung V, Latz E. 2010. Intracellular DNA recognition. Nat Rev Immunol 10:123-30.

Huston E, Lynch MJ, Mohamed A, Collins DM, Hill EV, MacLeod R, et al. 2008. EPAC and PKA allow cAMP dual control over DNA-PK nuclear translocation. Proc Natl Acad Sci USA 105:12791-6.

Ishii KJ, Coban C, Kato H, Takahashi K, Torii Y, Takeshita F, et al. 2006. A Toll-like receptor-independent antiviral response induced by double-stranded B-form DNA. Nat Immunol 7:40-8.

Ishii KJ, Kawagoe T, Koyama S, Matsui K, Kumar H, Kawai T, et al. 2008. TANK-binding kinase-1 delineates innate and adaptive immune responses to DNA vaccines. Nature 451:725-9.

Ishikawa H, Ma Z, Barber GN. 2009. STING regulates intracellular DNA-mediated, type I interferon-dependent innate immunity. Nature 461:788-92.

Karayel E, Bürckstümmer T, Bilban M, Dürnberger G, Weitzer S, Martinez J, et al. 2009. The TLR-independent DNA recognition pathway in murine macrophages: Ligand features and molecular signature. Eur $\mathrm{J}$ Immunol 39:1929-36.

Karpova AY, Trost M, Murray JM, Cantley LC, Howley PM. 2002. Interferon regulatory factor-3 is an in vivo target of DNA-PK. Proc Natl Acad Sci USA 99:2818-23.

Kawane K, Ohtani M, Miwa K, Kizawa T, Kanbara Y, Yoshioka Y, et al. 2006. Chronic polyarthritis caused by mammalian DNA that escapes from degradation in macrophages. Nature 443:998-1002.

Kimkong I, Avihingsanon Y, Hirankarn N. 2009. Expression profile of HIN200 in leukocytes and renal biopsy of SLE patients by real-time RT-PCR. Lupus 18:1066-72.

Kumar H, Kawai T, Kato H, Sato S, Takahashi K, Coban C, et al. 2006. Essential role of IPS-1 in innate immune responses against RNA viruses. J Exp Med 203:1795-803.

Law M, Carter GC, Roberts KL, Hollinshead M, Smith GL. 2006. Ligand-induced and nonfusogenic dissolution of a viral membrane. Proc Natl Acad Sci USA 103:5989-94.

Lee-Kirsch MA, Chowdhury D, Harvey S, Gong M, Senenko L, Engel K, et al. 2007a. A mutation in TREX1 that impairs susceptibility to granzyme A-mediated cell death underlies familial chilblain lupus. J Mol Med (Berl) 85:531-7. 
Lee-Kirsch MA, Gong M, Chowdhury D, Senenko L, Engel K, Lee YA, et al. 2007b. Mutations in the gene encoding the 3'-5' DNA exonuclease TREX1 are associated with systemic lupus erythematosus. Nat Genet 39:1065-7.

Lieber MR, Ma Y, Pannicke U, Schwarz K. 2003. Mechanism and regulation of human non-homologous DNA end-joining. Nat Rev Mol Cell Biol 4:712-20.

Medzhitov R. 2007. Recognition of microorganisms and activation of the immune response. Nature 449:819-26.

Moll U, Lau R, Sypes MA, Gupta MM, Anderson CW. 1999. DNA-PK, the DNA-activated protein kinase, is differentially expressed in normal and malignant human tissues. Oncogene 18:3114-26.

Moss B. 2007. Poxviridae: the viruses and their replication. In:Knipe DM, Howley DP, editors. Fields Virology. Philadelphia, PA: Lippincott Williams \& Wilkins. p. 2905-46.

Navarro L, Mowen K, Rodems S, Weaver B, Reich N, Spector D, et al. 1998. Cytomegalovirus activates interferon immediate-early response gene expression and an interferon regulatory factor 3-containing interferon-stimulated response element-binding complex. Mol Cell Biol 18:3796-802.

Nussenzweig A, Chen C, da Costa Soares V, Sanchez M, Sokol K, Nussenzweig MC, et al. 1996. Requirement for Ku80 in growth and immunoglobulin V(D)J recombination. Nature 382:551-5.

Oka T, Hikoso S, Yamaguchi O, Taneike M, Takeda T, Tamai T, et al. 2012. Mitochondrial DNA that escapes from autophagy causes inflammation and heart failure. Nature 10:251-5. doi: 10.1038/nature10992.

Okabe Y, Kawane K, Nagata S. 2008. IFN regulatory factor (IRF) 3/7-dependent and -independent gene induction by mammalian DNA that escapes degradation. Eur J Immunol 38:3150-8.

Paludan SR, Bowie AG, Horan KA, Fitzgerald KA. 2011. Recognition of herpesviruses by the innate immune system. Nat Rev Immunol 11:143-54.

Pichlmair A, Reis e Sousa C. 2007. Innate recognition of viruses. Immunity 27:370-83.

Rioux JD, Abbas AK. 2005. Paths to understanding the genetic basis of autoimmune disease. Nature 435:584-9.

Roberts TL, Idris A, Dunn JA, Kelly GM, Burnton CM, Hodgson S, et al. 2009. HIN-200 proteins regulate caspase activation in response to foreign cytoplasmic DNA. Science 323:1057-60.

Rupec RA, Poujol D, Grosgeorge J, Carle GF, Livolsi A, Peyron JF, et al. 1999. Structural analysis, expression, and chromosomal localization of the mouse ikba gene. Immunogenetics 49:395-403.

Schattgen SA, Fitzgerald KA. 2011. The PYHIN protein family as mediators of host defenses. Immunol Rev 243:109-8.

Sharma S, DeOliveira RB, Kalantari P, Parroche P, Goutagny N, Jiang Z, et al. 2011. Innate immune recognition of an AT-rich stem-loop DNA motif in the Plasmodium falciparum genome. Immunity 35:194-207.

Spurrell JC, Wiehler S, Zaheer RS, Sanders SP, Proud D. 2005. Human airway epithelial cells produce IP-10 (CXCL10) in vitro and in vivo upon rhinovirus infection. Am J Physiol Lung Cell Mol Physiol 289:L85-95.

Stetson DB, Medzhitov R. 2006. Recognition of cytosolic DNA activates an IRF3-dependent innate immune response. Immunity 24:93-103.

Stetson DB, Ko JS, Heidmann T, Medzhitov R. 2008. Trex1 prevents cell-intrinsic initiation of autoimmunity. Cell 134:587-98.

Takaoka A, Wang Z, Choi MK, Yanai H, Negishi H, Ban T, et al. 2007. DAI (DLM-1/ZBP1) is a cytosolic DNA sensor and an activator of innate immune response. Nature 448:501-5.

Unterholzner L, Keating SE, Baran M, Horan KA, Jensen SB, Sharma S, et al. 2010. IFI16 is an innate immune sensor for intracellular DNA. Nat Immunol 11:997-1004.

Upton JW, Kaiser WJ, Mocarski ES. 2012. DAI/ZBP1/DLM-1 complexes with RIP3 to mediate virus-induced programmed necrosis that is targeted by murine cytomegalovirus vIRA. Cell Host Microbe 11:290-7.

Versteeg GA, García-Sastre A. 2010. Viral tricks to grid-lock the type I interferon system. Curr Opin Microbiol 13:508-16.

Veuger SJ, Curtin NJ, Richardson CJ, Smith GC, Durkacz BW. 2003. Radiosensitization and DNA repair inhibition by the combined use of novel inhibitors of DNA-dependent protein kinase and poly(ADP-ribose) polymerase-1. Cancer Res 63:6008-15.

Walker JR, Corpina RA, Goldberg J. 2001. Structure of the Ku heterodimer bound to DNA and its implications for double-strand break repair. Nature 412:607-14.

Wang Z, Choi MK, Ban T, Yanai H, Negishi H, Lu Y, et al. 2008. Regulation of innate immune responses by DAI (DLM-1/ZBP1) and other DNA-sensing molecules. Proc Natl Acad Sci USA 105:5477-82.

Yaneva M, Kowalewski T, Lieber MR. 1997. Interaction of DNA-dependent protein kinase with DNA and with Ku: biochemical and atomic-force microscopy studies. EMBO J 16:5098-112.

Zhang X, Brann TW, Zhou M, Yang J, Oguariri RM, Lidie KB, et al. 2011a. Cutting edge: Ku70 is a novel cytosolic DNA sensor that induces type III rather than type I IFN. J Immunol 186:4541-5.

Zhang Z, Yuan B, Bao M, Lu N, Kim T, Liu YJ. 2011b. The helicase DDX41 senses intracellular DNA mediated by the adaptor STING in dendritic cells. Nat Immunol 12:959-65. 